THE PROPOSED EXPERIMENTAL TANK FOR TESTING SHIP MODELS FOR RESISTANCE.

THE recent opening of the National Physical Laboratory, as described in NATURE on March 27, marked an epoch in the advance of science into the commercial development of this country. Equipped as the Laboratory will be with the best appliances for testing materials and instruments of precision, for fixing standards of measurement and comparison, it will supply that which, in other countries, has already been recognised as a vital necessity to national commercial prosperity.

There is, however, a branch of scientific investigation not contemplated in the original scheme for the Physical Laboratory and which it is now proposed to include in it namely, an experimental tank for testing, by means of models, the resistance of vessels either already in existence or only in the stage of design.

The system followed in the practical application of theory to the solution of these problems of naval archi-

the trim of the model, when placed in the water, serves as a check on the accuracy of the workmanship.

The model, when ready for testing, is placed in the tank and attached to a travelling framework or "carriage" which spans the width of the tank and is propelled either by a self-contained motor or by a stationary engine and cable. The travelling carriage is fitted with a dynamometer and registering apparatus, which records automatically the pull or resistance of the model and the speed at every point of the course traversed. Thus, at the conclusion of a series of trial runs at different speeds, accurate diagrams are obtained, from which the curves of resistance can be plotted for the various speeds considered, and, by interpolation, for any intermediate speed. In a similar way, the effect of alteration of trim and displacement can be easily determined, and the most interesting and useful experiments on the effect of alterations to existing vessels, on the efficiency of various forms of screw propellers, on the relative oscillations of different types of hull, and many other problems that are met with in naval architecture can be carried out with results that approximate closely enough for all practical requirements to those actually obtained on full-sized ships. The economy in

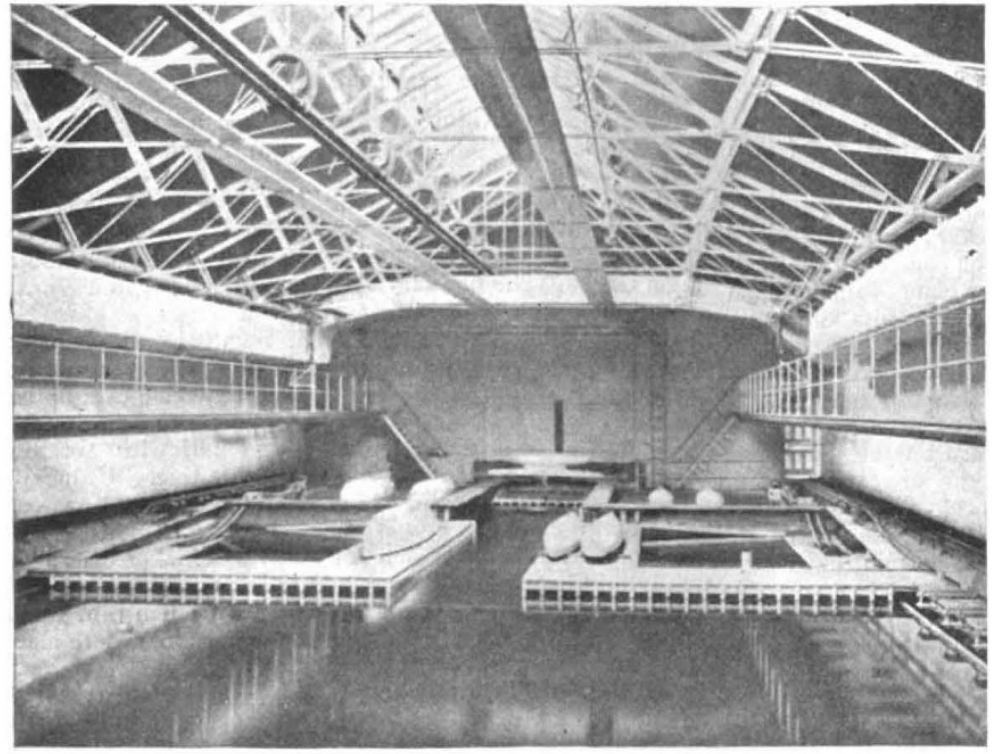

FIG. I. - View of Washington Tank, north end, showing Wave Breaker. using models instead of full-sized vessels for obtaining such experimental data is sufficiently obvious, and need not be insisted upon.

It is to Mr. Froude also that we are indebted for establishing the exact relations that subsist between the model and the full-sized vessel, upon which depends the success of the experimental method. This relation or law of "corresponding speeds" is to the effect that, comparing ship and model, "the resistance is in proportion to the cube of the linear dimension at speeds proportional to the square root of the linear dimension."

The practical value of Mr. Froude's labours was recognised by the Government at an early period, and his tank at Torquay was established under Admiralty supervision in 1870 . Fifteen years later, the Government decided to build and equip a much larger tank at Haslar, near Portsmouth, where models I 4 feet long could be run over a course of 400 feet. This tank is under the direction of Mr. R. E. Froude, whose valuable researches by means of model experiments have greatly added to our

tecture was devised by the late $\mathrm{Mr}$. Wm. Froude. In his first experimental tank, erected at Torquay more than thirty years ago, Mr. Froude carried out the researches which led to his well-known discovery of the laws which govern the resistance offered by water to the propulsion of ships.

Although the method pursued has often been described in NATURE and elsewhere, a brief outline of it, by way of reminder to our readers, may not be out of place.

A model of the vessel the resistance of which is to be tested is made either of wood or, preferably, of paraffin. If the latter material is used, the block is cast roughly to the shape of the proposed hull and then placed in a cutting machine, where it is planed down to the exact shape required, by a cutting tool, the movements of which are controlled by the operator. The latter guides the instrument by following with a pointer the lines of the hull on a drawing, the connection between the pointer and the cutting tool being so exact that the contour lines of the design are faithfully reproduced on the hull of the model. The final touches are done by hand, and NO. I 70 I, VOL. 66] knowledge of the laws relating to fluid resistance, oscillation of ships, propeller efficiency, and other problems of naval architecture.

The tank at Haslar, erected at Government expense, has been devoted purely to Admiralty work, and it is not found possible to extend its use to the testing of models for private shipbuilders.

The only other tank of this kind in the kingdom is that constructed by Messrs. Denny at Dumbarton, and this is only employed upon the work of that firm.

Recognising the need for a tank where private ship. builders could at any time send a model to be tested, the Institution of Naval Architects, at their summer meeting in Glasgow last year, passed a resolution to the effect that such a tank ought to be established, and the council of that Institution has since been considering how this proposal could best be carried out.

The two chief difficulties were the selection of a site suitable for the purpose and the raising of the necessary funds to carry the scheme out. As regards the latter requirement, it was felt that those interested in the welfare of the shipowning and shipbuilding interests of 
the country would not be slow to guarantee the necessary funds, provided a site could be found easily accessible, and where a tank could be placed under independent, competent and impartial control.

In the grounds of the National Physical Laboratory

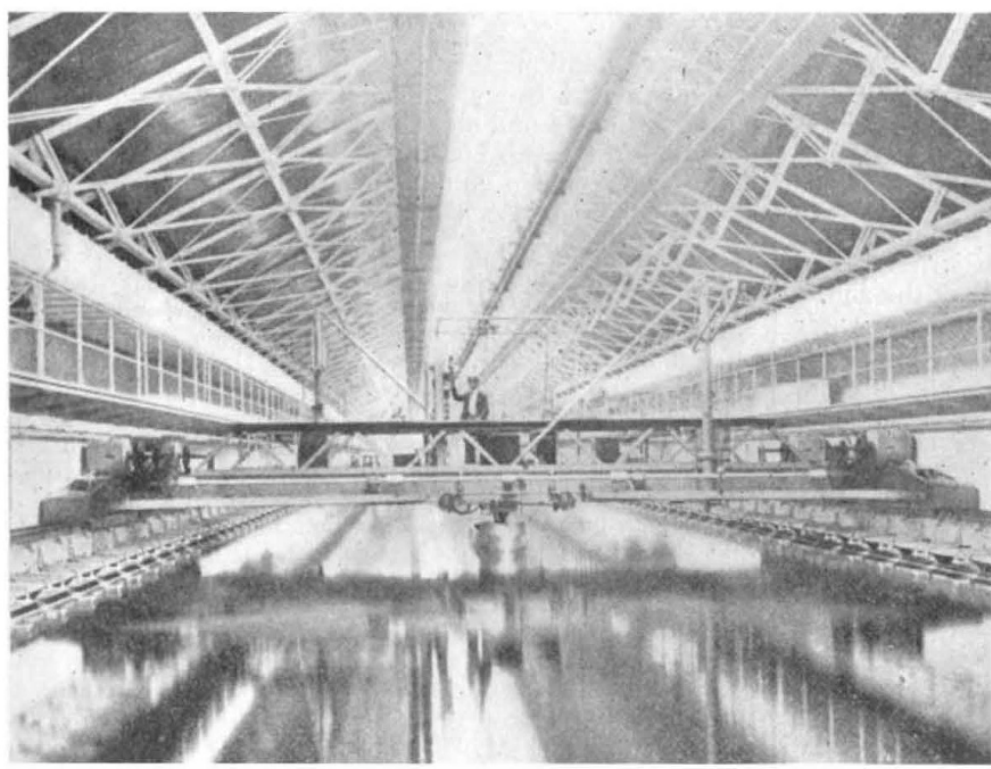

$\mathrm{F}_{1 \mathrm{G} .}$ 2,- - View of Carriage and Model at rest.

at Bushy House, a site has been selected which it is proposed to devote to the purpose. This situation, besides being very convenient as regards the nature of the ground (to quote from Lord Glasgow's recent presidential address), offers "many important advantages ; a position conveniently near the metropolis, the proximity of an established power installation and a highly trained technical staff, and, above all, a board of management of the highest standing, entirely unconnected with any individual commercial enterprise, whose control would in itself guarantee the treatment in strictest confidence and impartiality of all questions submitted to them."

It is hoped, therefore, that shipbuilders and shipowners and others will come forward liberally to form the necessary guarantee fund for the construction and equipment of the tank, which together are estimated to cost about 15,000 l. The scheme, which has received the hearty support of His Royal Highness the Prince of Wales, is now ripe for carrying into execution, and it is felt that no more time should be lost in adding this necessary auxiliary to the equipment of British shipyards. The Prince of Wales, in opening the Laboratory on March 19, expressed his confidence-a confidence which we feel sure will be justified by results-that "through the generosity of the public, the necessary means will be forthcoming to meet these difficulties and to secure that which is almost an essential to the shipbuilding industry of a country possessing the largest mercantile marine in the world."

No. I7OI, VOL. 66]
Other countries have not been slow to realise the value of model experiments; Italy has her experimental tank at Spezia ; Russia one at St. Petersburg; Germany, besides having a private tank at Bremerhaven belonging to the Norddeutscher Lloyd, is about to erect one in Berlin; and the United States of America, not to be outdone by the old countries, has built the largest tank of all at Washington, where 20 -feet models are tested over a 470-feet length of run.

All these tanks, excepting that at Bremerhaven, are worked by Admiralty staffs of their respective Governments, but the private shipbuilder has not been forgotten, and in each case he may, subject to certain regulations and to the payment of fees sufficient to cover the cost of the experiments, make free use of the tank for carrying out researches of his own. But, however convenient it may be to have a tank erected at the expense of a paternal Government, it can hardly be doubted that the arrangement has its drawbacks; private individuals would, at times of pressure, have to give way to Government needs, and at all times the results of the experiments are of necessity obtained as much for the benefit of the Admiralty as for that of the private individual. Both these drawbacks are obviated by placing the management of the tank in private, but disinterested, hands.

Some views of the Washington tank are reproduced here from a paper by Mr. D. W. Taylor (naval constructor, U.S.N.), read before the American Society of Naval Architects and Marine Engineers, and they give a good idea of its chief features of interest. The "carriage,"

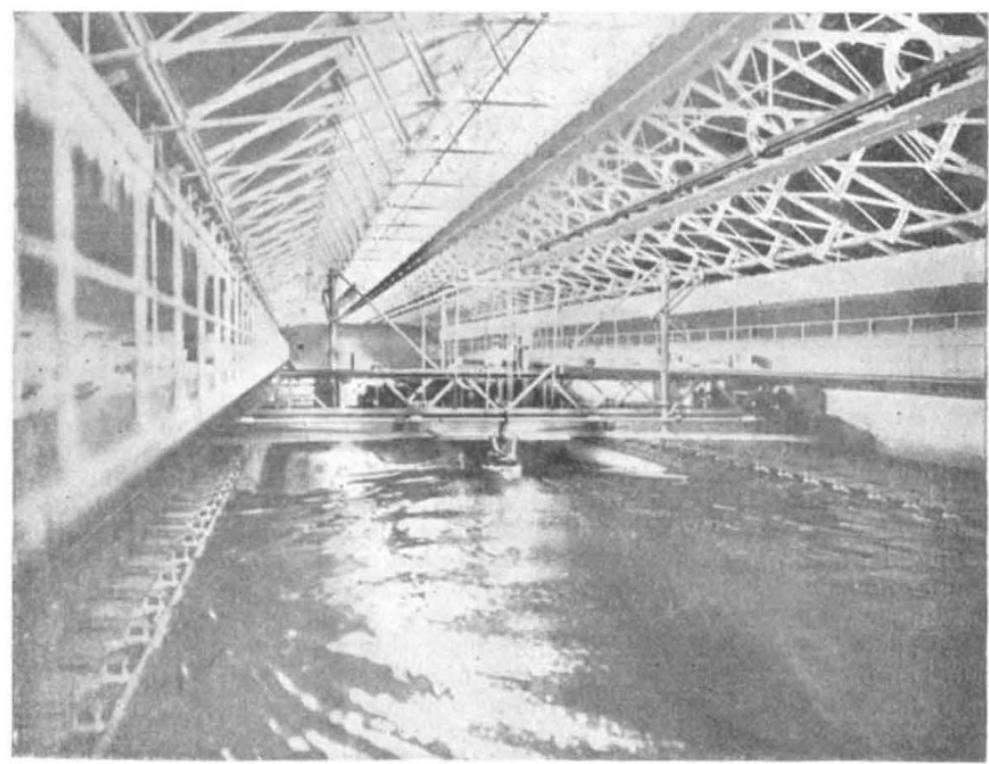

FIG. 3.-Carriage towing a Model (stern view).

which draws the model through the water and contains the recording apparatus, spans the entire width of the tank ( 46 feet 6 inches) and weighs nearly thirty-two tons. It is propelled by four electric motors, shown in Fig. 2 at 
the extreme ends of the framework. As the speed attainable is upwards of 20 knots - developed in a 200 -feet runpowerful emergency brakes actuated by hydraulic pressure are provided, in addition to the ordinary friction brakes, and the whole carriage is under perfect control for stopping and starting, and maintaining constant speed during a run.

The extreme length of water surface in the Washington tank is 470 feet, of which about 370 is of the full section across, the remainder being the narrow extremities available for starting and stopping. In order to reduce the time lost between runs through waiting to obtain still water, side troughs 12 inches square in section are laid throughout the length of the tank to absorb the wave disturbance caused by a model run, while at the north end of the tank (Fig. I) a series of wooden strips placed vertically act as a wave breaker at the close of the run.

Great care is taken to ensure the purity of the water by treating it with alum and filtering through sand

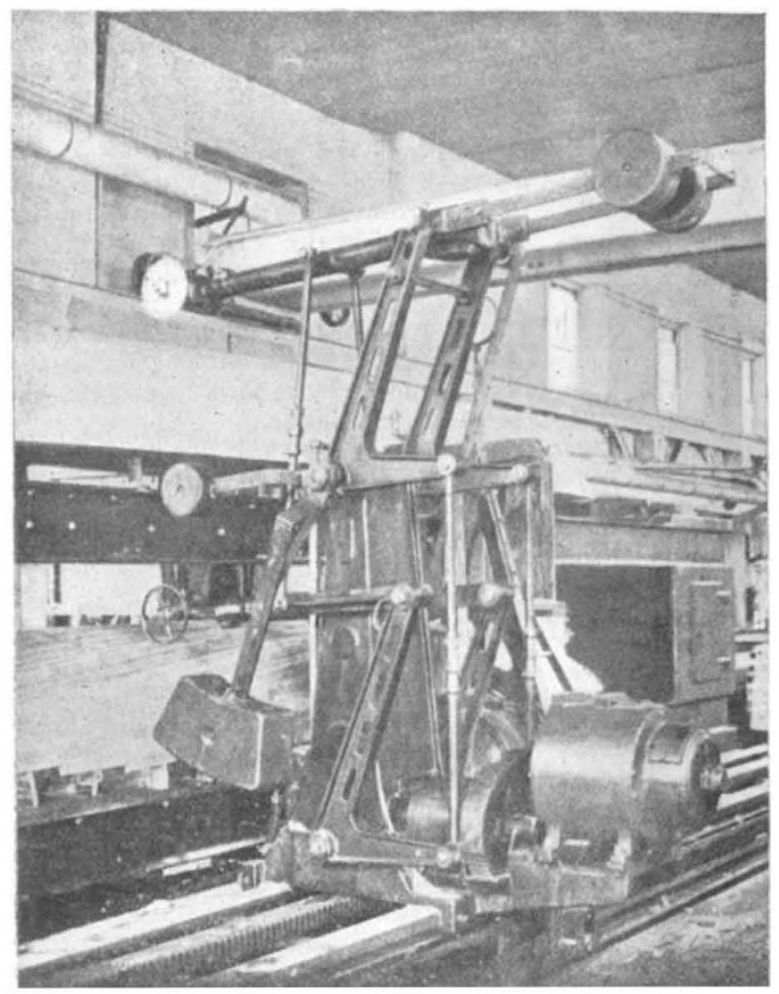

FIG. 4.-Model Shaping Machine.

before admission to the tank. The capacity of the latter is about one million gallons, and the tank can be pumped dry when required in about four hours by a 12 -inch centrifugal pump. The temperature in the building is kept as far as possible uniform and slightly above that of an ordinary living room.

A special feature at the Washington establishment is the employment of wood for the models instead of paraffin. This is on account of the heat in summer being too great to allow of the latter material being used, preferable though it is in other respects ; for the cost of wood is higher, the difficulties of shaping it to the specified lines are greater, more time is required, and it is, of course, impossible to reduce it to bulk after use, as in the case of paraffin. On the other hand, a wooden model is less liable to accidental damage and retains its shape better if required for future use.
Fig. 3 shows a model being towed through the water, the wave formation being clearly visible ; Fig. 4 gives a view of the shaping machine at work on a model.

$$
\text { R. W. D. }
$$

\section{VOLCANIC DUST FROM THE WEST INDIES.}

$\mathrm{T}$ was mentioned last week that the West Indian mails had brought packets of volcanic dust which fell at Barbados and elsewhere to several institutions and investigators in this country. The characteristics of this material have been minutely examined, and the following descriptions of them will be found of interest.

\section{I.}

At the meeting of the Geological Society on Wednesday, May 28, Dr. Flett communicated a preliminary note on the ash which fell at Barbados. The specimens had been forwarded by Dr. Morris, of the Imperial Department of Agriculture, to Prof. Judd, who placed them in the hands of Dr. Flett for examination. The ash consists principally of plagioclase felspar allied to labradorite, hypersthene, monoclinic augite and magnetite. The crystals are often perfectly idiomorphic, and it may be safely inferred that they were formed in the magma before the actual eruption took place, and blown into the air along with the molten material by the force of the escaping gases. A small amount of glass containing steam holes is adherent to some of the crystals, but many are perfectly clean.

The crystals are similar in every respect to the phenocrysts of hypersthene-augite-andesite, a type of rock well known among the recent volcanoes of the Pacific region. In the discussion which followed the reading of Dr. Flett's paper, it was pointed out by Mr. Prior that the same type of rock occurs in other West Indian islands, and also in the Mexican volcanoes, so that the petrographical evidence serves to connect the West Indian volcanic region with the Pacific rather than with the Atlantic. An analysis of the ash by Dr. Pollard was communicated by Dr. Flett. It is quoted below.

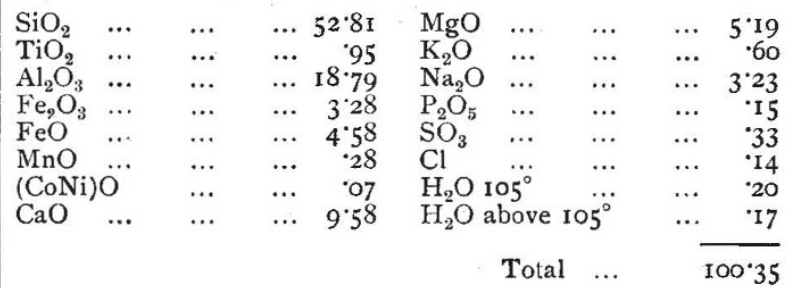

It must be remembered that this analysis does not represent the composition of the material as it existed in the subterranean reservoir immediately before the eruption, but rather the bulk analysis of the crystals which had separated out, together with only a small admixture of the glass.

If this glass could be separated and analysed it would probably be found to differ from the bulk analysis of the crystals in the same way as the glassy base of hypersthene-andesites differs from the bulk analysis of the phenocrysts; that is, it would contain more silica, less lime, iron and magnesia, and more alkalis, especially potash. In Old Red Sandstone times the volcanoes of the Cheviot district erupted hyperstheneandesites, and the glassy base of one of these rocks was analysed by Dr. Petersen with the following result :-

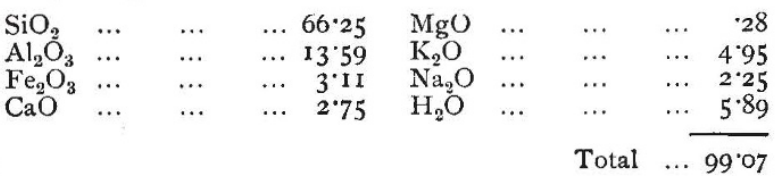

The samples of ash from Barbados hitherto examined consist mainly of the crystals. The glassy matter which represents the mother liquor appears to have been vanned away and deposited elsewhere. This, if it should turn out to be the case, is somewhat unfortunate, for the glass, with its higher percentage of potash, would have been more useful as a fertilising agent.
J. J. H. TEALL.

NO. I 7OI, VOL. 66] 